\title{
7 Pathogenesis and Progression of Multiple Sclerosis: The Role of Arachidonic Acid-Mediated Neuroinflammation
}

\section{SARA PALUMBO}

Department of Surgical, Medical, Molecular Pathology and Critical Care, University of Pisa, Pisa, Italy

Author for correspondence: Sara Palumbo, Department of Surgical, Medical, Molecular Pathology and Critical Care, University of Pisa, via Savi 10, I-56126, Pisa, Italy. E-mail: sara.palumbo@for.unipi.it

Doi: http://dx.doi.org/10.15586/codon.multiplesclerosis.2017.ch7

Abstract: Multiple sclerosis is characterized by inflammatory processes occurring within the central nervous system. In multiple sclerosis, inflammation could be either a physiological response secondary to the immune system activation or a phenomenon triggered by primary cytodegeneration of neurons and/ or oligodendrocytes without the involvement of immune cells. The arachidonic acid metabolism is activated via cyclooxygenases (COXs) and lipoxygenases (LOXs) in postmortem brain samples and in the cerebrospinal fluid of multiple sclerosis patients. It has been hypothesized that the arachidonic acid-mediated neuroinflammation could play a role in the pathogenic mechanisms triggering demyelination, oligodendrocyte loss, axonal pathology and, ultimately, motor dysfunctions, which are hallmarks of multiple sclerosis. COX-2 and 5-LOX selective inhibitors efficiently inhibit each of the hallmarks mentioned above in different animal models of multiple sclerosis. Thus, it is suggested that the arachidonic acid pathway represents a potential pharmacological target to ameliorate multiple sclerosis pathology and symptoms.

In: Multiple Sclerosis: Perspectives in Treatment and Pathogenesis. Ian S. Zagon and Patricia J. McLaughlin (Editors), Codon Publications, Brisbane, Australia. ISBN: 978-0-9944381-3-3; Doi: http://dx.doi.org/10.15586/codon.multiplesclerosis.2017

Copyright: The Authors.

Licence: This open access article is licenced under Creative Commons Attribution 4.0 International (CC BY-NC 4.0). https://creativecommons.org/licenses/by-nc/4.0/ 
Key words: Arachidonic acid; Cyclooxygenases; Inflammation; Lipoxygenases; Multiple sclerosis

\section{Introduction}

Multiple sclerosis is a multifactorial degenerative disease of the central nervous system characterized by immune system activation, inflammation, and demyelination. The genesis of the inflammatory process and its role in the onset and progression of the disease is still under debate, although advances have been made over the past decades of scientific research. For instance, it has been hypothesized that the central inflammation observed in multiple sclerosis is a physiological response secondary to the immune system activation. Different subtypes of $\mathrm{CD}^{+} \mathrm{T}$ helper lymphocytes-Th1 and Th17-and cytotoxic $\mathrm{CD} 8^{+}$lymphocytes have been shown to trigger neuroinflammation in multiple sclerosis (1). These activated lymphocytes migrate to the brain, recall peripheral monocytes/macrophages, and ultimately lead to myelin loss and apoptosis and/ or necrosis of mature oligodendrocytes. Resident astrocytes and microglia are activated after lymphocytes infiltration. As a consequence, several inflammatory mediators like cytokines (chemokines, IL2, IL3, TNF $\alpha$, IFN $\gamma$, and many others) are released by these cells in the extracellular compartment where they exert cytotoxic activity against oligodendrocytes (2-5).

In some types of multiple sclerosis, the disease seems to develop independently of the autoimmune mechanisms, particularity in those disease types-histological patterns III and IV - that show no evidence of immune activation at demyelinated lesions $(6,7)$. In these cases, inflammation maybe triggered by primary cytodegeneration of neurons and/or oligodendrocytes without the involvement of immune cells (8). Regardless of the biological process underlying inflammation, it has been consistently shown that inflammation is directly involved in the progression of multiple sclerosis (9). In recent years, there has been a growing interest in understanding the role of inflammatory mediators derived from the activation of arachidonic acid metabolism (e.g., prostaglandins and leukotrienes) in the disease (10). Prostaglandins and leukotrienes are abundantly produced in the central nervous system of multiple sclerosis patients, contributing to the severity of the disease. Therefore, it has been suggested that anti-inflammatory treatments targeting the arachidonic acid pathway, by using nonsteroidal anti-inflammatory drugs (NSAIDs), might be beneficial for treating multiple sclerosis.

\section{Activation of the Arachidonic Acid Cascade in Multiple Sclerosis}

Scientific evidences show that arachidonic acid metabolism is excessively activated in the central nervous system of multiple sclerosis patients as well as in the brain of animals from experimental models of multiple sclerosis. It has been hypothesized that arachidonic acid products could play a role in the pathogenic mechanisms underlying demyelination, oligodendrocytes loss, and axonal pathology that represent common hallmarks of multiple sclerosis. Arachidonic acid is a 


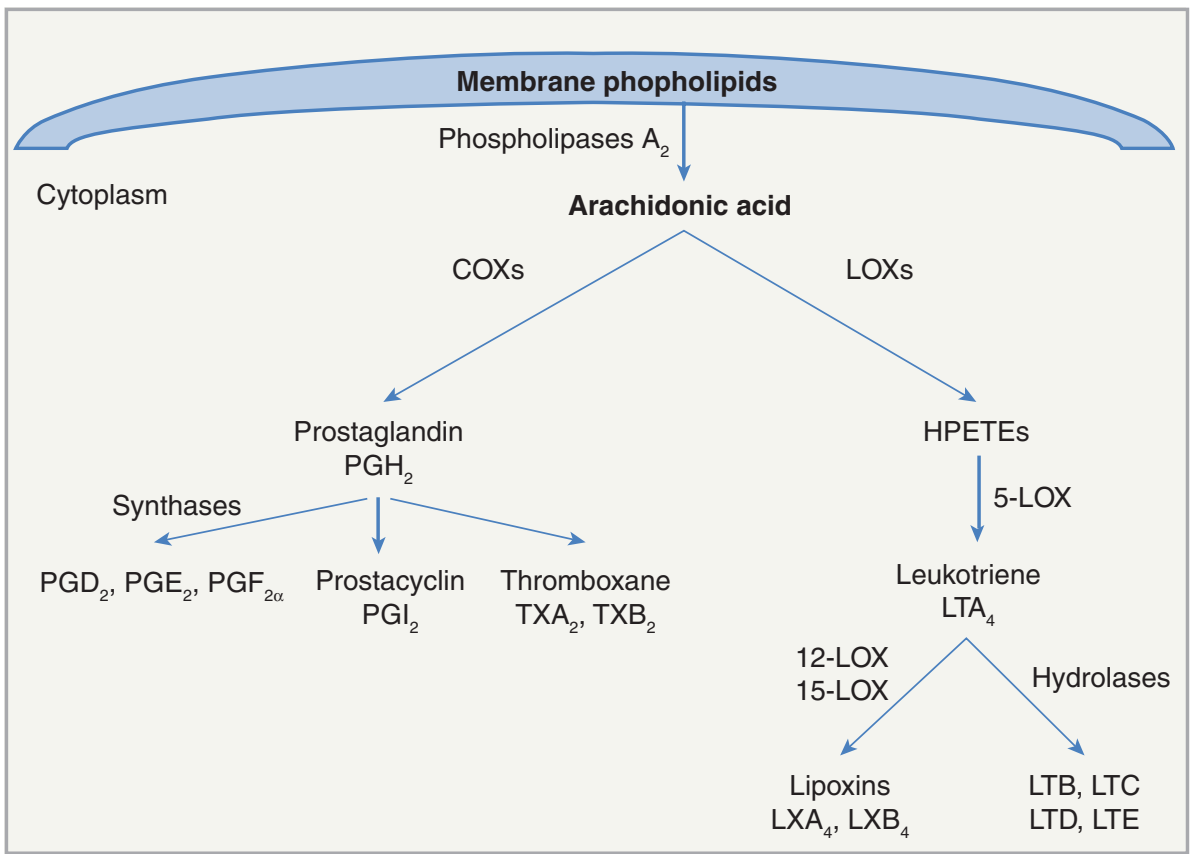

Figure 1 Schematic representation of the arachidonic acid metabolic pathway.

$\mathrm{COX}=$ cyclooxygenase, $\mathrm{LOX}=$ lipoxygenase, $\mathrm{HPETE}=$ hydroperoxyeicosatetraenoic acid.

membrane omega- 6 fatty acid molecule released in the cytoplasm by the hydrolytic activity of the cytosolic phospholipase $\mathrm{A}_{2}\left(\mathrm{cPLA}_{2}\right)$ (Figure 1 ). It has been shown that the concentration of several molecules that activate $\mathrm{CPLA}_{2}$, such as reactive oxygen species and cytokines, is increased in multiple sclerosis (11-14). After being released into the cytoplasm, arachidonic acid is metabolized by the activity of cyclooxygenases (COXs) 1 and 2 into prostacyclins, prostaglandins (PGs), and thromboxanes (TXs), and by the lipoxygenases (LOXs), 5-LOX, 12-LOX and/or 15-LOX into leukotrienes (LTs) and lipoxins (LXs). As far as COXs are concerned, both isoforms lead to the production of $\mathrm{PGE}_{2}$. COX-1 is constitutively expressed, whereas COX-2 is induced during inflammation and seems to be the major source of $\mathrm{PGE}_{2}$ production. Particularly, COX-2 expression appears to be induced in oligodendrocytes and immune cells during the processes of demyelination (15-17). The proinflammatory PGs and LTs that are upregulated in multiple sclerosis represent promising therapeutic targets as suggested by animal models of multiple sclerosis.

\section{ARACHIDONIC ACID PATHWAY ACTIVATION IN PATIENTS AFFECTED BY MULTIPLE SCLEROSIS}

Arachidonic acid activation has been found in the cerebrospinal fluid and in postmortem brain of multiple sclerosis patients (see Table 1 for details of primary data). It has been shown that COX-2 is expressed in active demyelinating lesions (15), and also in dying oligodendrocytes (16) suggesting a potential role for 


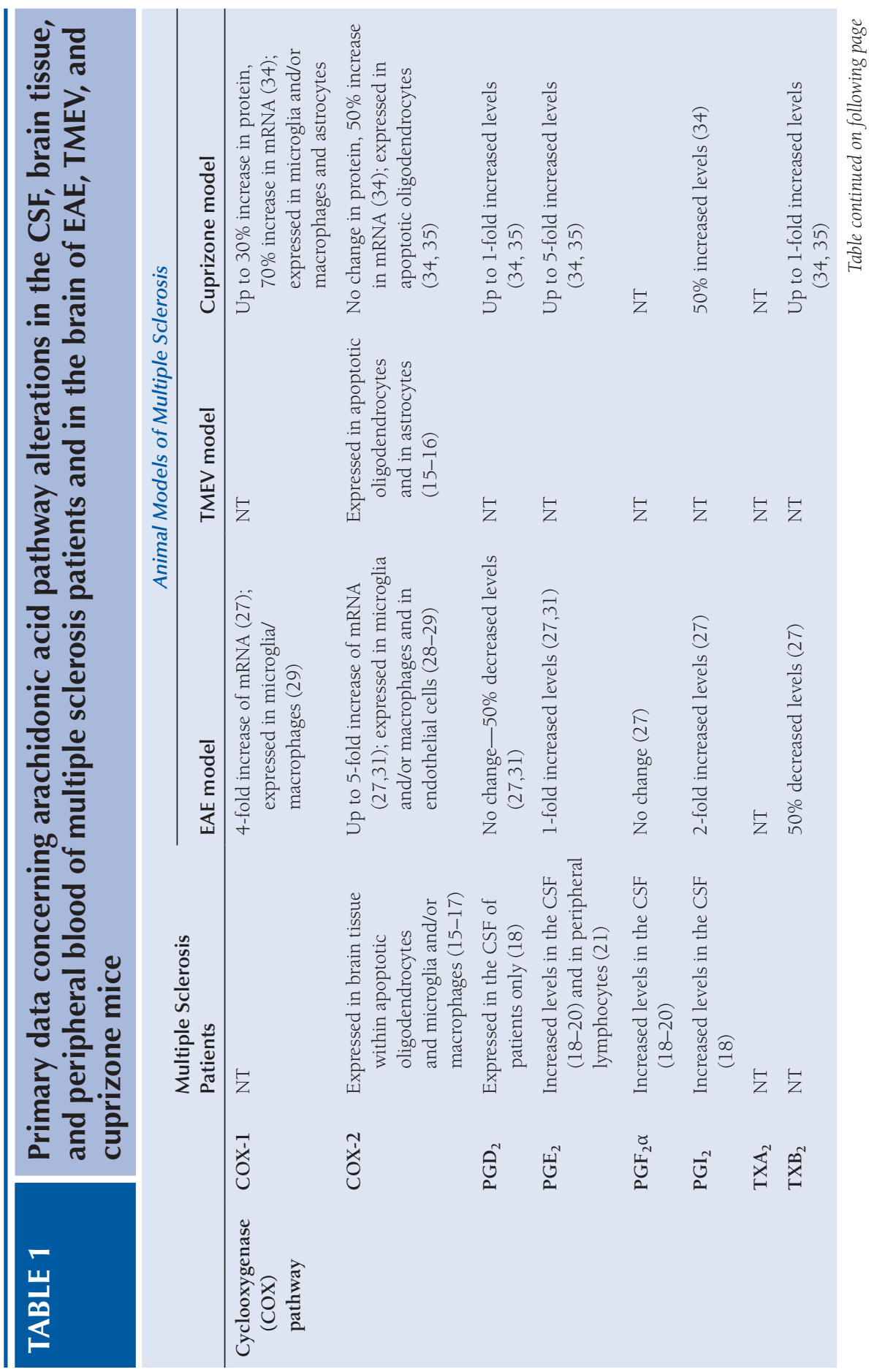




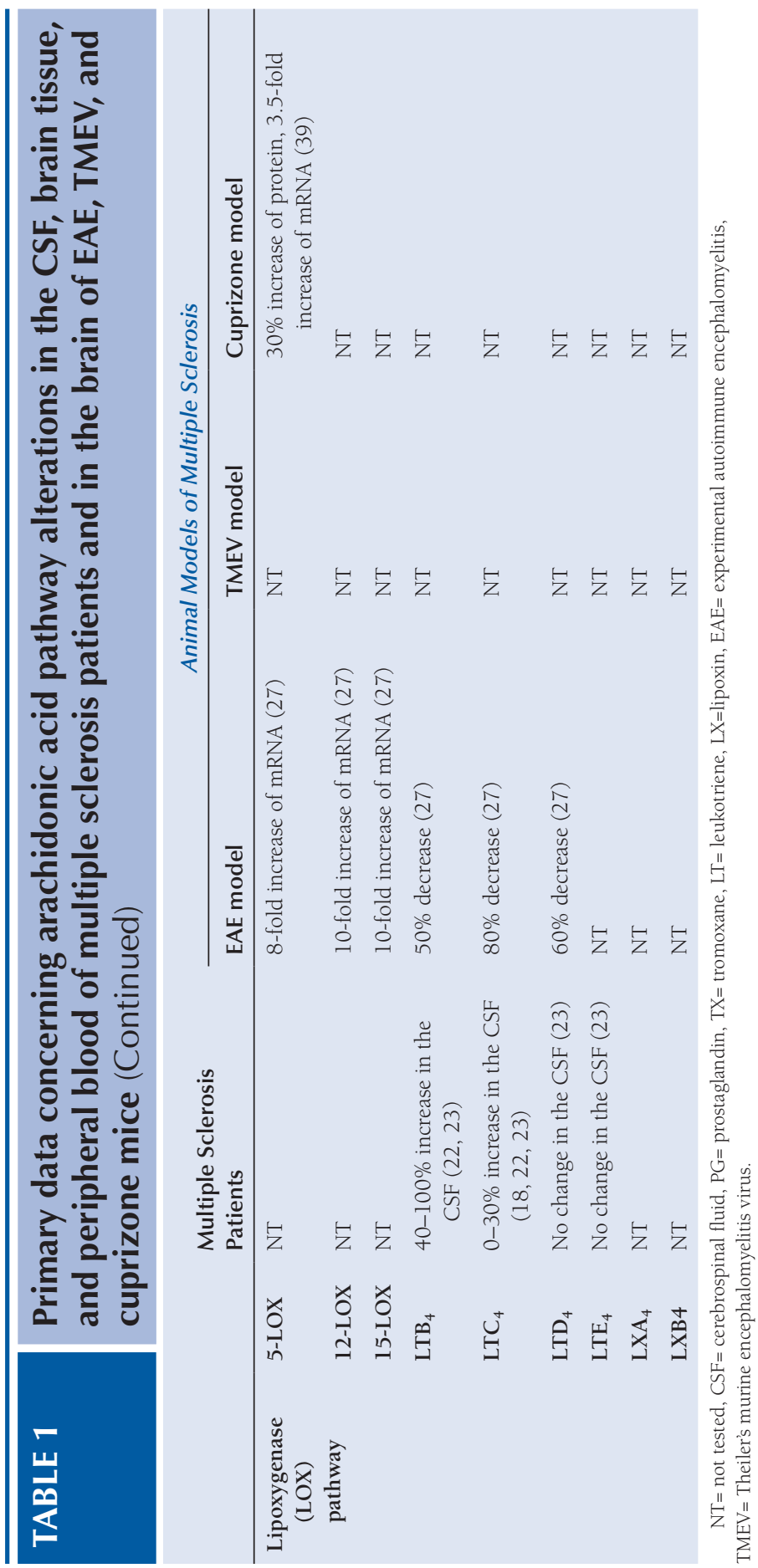


COX-2 in the biological mechanisms underlying the death of oligodendrocytes. Moreover, COX-2 is also expressed by inflammatory cells like macrophages and microglia that are located at active lesions (17). These data are in line with previous findings showing that COX-derived prostaglandins are excessively produced in the central nervous system of multiple sclerosis patients. The levels of prostaglandins $\mathrm{PGD}_{2}, \mathrm{PGE}_{2}$, and $\mathrm{PGF}_{2}$, and prostacyclin $\mathrm{PGI}_{2}$, were upregulated in the cerebrospinal fluid of patients during relapsing and remitting phases (18-20). $\mathrm{PGE}_{2}$ levels were also elevated in lymphocytes extracted from the peripheral blood of patients; the highest levels were reached at the onset of the disease or just before symptoms, suggesting that $\mathrm{PGE}_{2}$ could be involved in disease initiation (21).

As far as the metabolism of arachidonic acid by LOX enzymes is concerned, the levels of $\mathrm{LTB}_{4}$ and $\mathrm{LTC}_{4}$ in the cerebrospinal fluid of multiple sclerosis patients were elevated $(18,22)$. The same authors, in their second publication on the same topic, were able to replicate the results for $\mathrm{LTB}_{4}$, but not for $\mathrm{LTC}_{4}, \mathrm{LTD}_{4}$, and $\mathrm{LTE}_{4}$ levels (23). Overall, these data have suggested that, in multiple sclerosis, the metabolism of arachidonic acid through 5-LOX enzymatic activity was augmented. In 2010, a study, conducted in postmortem white matter specimens of multiple sclerosis patients, identified the 5-LOX gene as a top risk gene for multiple sclerosis (24).

\section{ARACHIDONIC ACID PATHWAY ACTIVATION IN ANIMAL MODELS OF MULTIPLE SCLEROSIS}

The arachidonic acid metabolic pathway is activated in three different animal models of multiple sclerosis: the experimental autoimmune encephalomyelitis (EAE), the Theiler's murine encephalomyelitis virus (TMEV), and the cuprizone model (see Table 1 for details of primary data). In the EAE model, the upstream enzyme $\mathrm{CPLA}_{2}$ has been shown to play a key role in the pathogenesis of the disease as $\mathrm{CPLA}_{2}$ knockout mice and naive mice treated with a $\mathrm{CPLA}_{2}$ specific inhibitor were both resistant to EAE induction $(25,26)$. Downstream $\mathrm{CPLA}_{2}, \mathrm{COX}-2$, inducible $\mathrm{PGE}_{2}$ synthase, and $\mathrm{PGE}_{2}$ levels were all increased in the brain of EAE mice (27). COX-2 was expressed in the resident microglia, infiltrating macrophages, and endothelial cells of the brain of EAE mice (28-29). Concerning the four receptors of $\mathrm{PGE}_{2}$, EP1, EP2, and EP4 were upregulated by one-, two-, and threefold, respectively (30). EP2 and EP4 have been implicated in the stimulation of lymphocytes CD4+ release and their activation in EAE model (30). Moreover, COX-1 expression and $\mathrm{PGI}_{2}$ levels were upregulated in the brain of EAE mice, whereas the concentration of $\mathrm{PGD}_{2}$ was downregulated, and the concentration of $\mathrm{PGF}_{2 \alpha}$ was unchanged (27). However, one study conducted in a chronic relapsing type of EAE showed conflicting findings. While the increase of COX-1, COX-2, and $\mathrm{PGE}_{2}$ was confirmed, the $\mathrm{PGD}_{2}$ levels remained unchanged in all the analyzed brain tissues (cerebral cortex, cerebellum, and spinal cord) (31). Interestingly, the increase of COX-2 expression and $\mathrm{PGE}_{2}$ levels was observed in early stages of the disease (31), suggesting a pathogenic role.

In the TMEV model, COX-2 expression was observed in the spinal cord (15). Specifically, COX-2 was expressed in oligodendrocytes undergoing apoptosis as indicated by immunohistochemistry experiments that found colocalization of the COX-2 protein and the apoptotic mediator caspase-3. These data were confirmed 
in a further study published in 2010 (16). The latter also showed that COX-2 mediates mechanisms of excitotoxicity against cultured oligodendrocytes (16). COX-2 and $\mathrm{PGE}_{2}$ gene expression were also found in primary cultures of astrocytes from TMEV-infected mice (32). The inhibition of $\mathrm{PGE}_{2}$ signaling at a downstream level using AH23848, which is a mixed EP1 and EP4 inhibitor, resulted in decreased pathogenesis of demyelinating disease (about 20\% decrease) and severity of viral load (about 85\% decrease) in the central nervous system (33).

Similar results were obtained in the cuprizone model of demyelination. Cuprizone takes about 5 to 6 weeks to induce a maximum demyelination in the brain, but oligodendrocytes express apoptotic markers earlier, starting from the first week of intoxication (34). In the brain of cuprizone-treated mice, both COX-1 and COX-2 were significantly upregulated, but the change in the expression showed different courses (34). COX-2 gene expression was found to be upregulated in the early phases of the cuprizone treatment when demyelination was not yet detectable, whereas COX-1 was upregulated later on at the peak of astrogliosis and microglia and/or macrophages activation concomitantly with severe demyelination (34). Interestingly, this observation led to the hypothesis that COX-2 precedes oligodendrocytes loss and is involved in the apoptotic processes. COX-2 was expressed in apoptotic caspase-3-expressing oligodendrocytes as early as after 1 week of cuprizone treatment (35). Further investigation in the COX-2 pathway showed that the cortical levels of several prostaglandins $\left(\mathrm{PGE}_{2}, \mathrm{PGD}_{2}, \mathrm{PGI}_{2}\right.$, and $\mathrm{TXB}_{2}$ ), were upregulated $(34,35)$. The increase in $\mathrm{PGE}_{2}$ concentration was more than the other prostaglandins, and the expression of its receptors, EP1, EP2, and EP4, was upregulated at the peak of demyelination (35). Interestingly, only EP2 protein expression was increased in the early stage, after 1 week of cuprizone treatment, and has been implicated in the initiation of demyelination and oligodendrocytes loss (35).

Regarding LOXs, there is an increasing consent supporting the role of 5-LOX and its downstream products in the mechanisms of immune cell recall in the brain, and in the development of axonal damage and of motor disabilities. The 5-LOX gene was found to be a top risk gene in EAE (24). The brain concentrations of 5-LOX products, $\mathrm{LTB}_{4}$ and $\mathrm{LTD}_{4}$, were upregulated $(18,22-23)$, and favored the migration of inflammatory cells and lymphocytes in the brain of EAE mice (36-38). In the cuprizone model, the brain expression of 5-LOX was highly increased (39). In addition, 5-LOX has been implicated in cuprizone-mediated axonal damage and motor dysfunction development (39). Overall, the data generated from the animal research indicate that the arachidonic acid pathway contributes to the development of multiple sclerosis-like pathology, especially via COX-2 and 5-LOX metabolism.

\section{Anti-inflammatory Therapy in Multiple Sclerosis}

Arachidonic acid-mediated inflammation is typically inhibited with nonsteroidal anti-inflammatory drugs (NSAIDs). NSAIDs have variable specificity against the two isoforms of COX. While some NSAIDs (e.g., ibuprofen, indomethacin, and naproxen), have mixed inhibitory effect on both COX-1 and COX-2 others, like the coxibs (e.g., celecoxib, rofecoxib, and valdecoxib) and nimesulide, specifically inhibit COX-2 (40). NSAIDs have been administered to patients affected by 
multiple sclerosis to counteract symptoms related to flu, but no clinical trials have ever evaluated whether NSAIDs could reduce multiple sclerosis pathology as well. Animal models of multiple sclerosis have demonstrated the beneficial effects of NSAIDs. Furthermore, the pharmacological inhibition of LOX-mediated metabolism of arachidonic acid exerts some beneficial effects. The following paragraphs describe the available evidence on the potential of COX and LOX inhibitors as therapeutics for multiple sclerosis.

\section{NSAIDs TREATMENT IN PATIENTS AFFECTED BY MULTIPLE SCLEROSIS}

It is not known whether NSAIDs have an inhibitory effect on the pathology of multiple sclerosis. To date, NSAIDs have been administered to patients to treat flu-like symptoms without taking into consideration of their potential role in oligodendrocytes survival and myelin protection (41-46). Nevertheless, some NSAIDs were shown to ameliorate fatigue (approximate percentage of improvement: 10-20\% with aspirin, 30\% with naproxen, and 20\% with ibuprofen) and improve cognitive abilities (approximate fold change of improvement: 1-fold with naproxen, 0.5-fold with ibuprofen, and 2-fold with acetaminophen) (46, 47). It could be hypothesized that these effects may be secondary to the attenuation of brain pathology due to NSAIDs treatment, as suggested by the following data from experimental models of multiple sclerosis.

\section{EFFECT OF NSAIDs IN ANIMAL MODELS OF MULTIPLE SCLEROSIS}

Non-selective COX inhibitors and COX-2 selective drugs have shown protective effects in EAE, cuprizone and TMEV murine models of multiple sclerosis. In the EAE model, mixed COX-1/2 inhibitors (indometacin and naproxen) delayed the onset (about 8 days delay with naproxen) and the severity of the disease (about 30\% improvement with indometacin and 70\% with naproxen) $(26,48,49)$. In the cuprizone model, COX-1 knockout mice normally develop demyelination in the same extent as matched wild type mice, indicating that COX-1 is not involved in the demyelination process. Conversely, knocking out the COX-2 gene inhibited demyelination (about 40\% inhibition in the corpus callosum and complete recovery in the cortex) and restored motor functions (35).

Selective targeting of COX-2 has provided a large number of evidence, supporting the prominent role of this isoform in disease initiation and severity. The administration of selective COX-2 inhibitors (LM01, LM08, LM11, and NS398), or coxibs (rofecoxib, celecoxib, and lumiracoxib) interfered with EAE induction by decreasing physical dysfunctions, inflammation, and demyelination; the protective effects of these compounds were mediated through the inhibition of adhesion and chemoattractant molecules, and the reduction of monocyte infiltration (48-51). Specifically, LM01, LM08, LM11, and NS398 inhibited the paralysis period (percentage inhibition: $48,95,76$, and 43 , respectively), inflammation (percentage inhibition: 85, 84, 78, and 81, respectively), and demyelination (percentage inhibition: $74,67,53$, and 61 , respectively) (50). Celecoxib prevented EAE induction, reduced the expression of adhesion and chemoattractant 
molecules (histological nonquantitative data), and inhibited the number of infiltrating monocytes (49). Rofecoxib and lumiracoxib reduced inflammation by $90 \%$ and $85 \%$, respectively (51).

In the TMEV model, the COX-2 selective inhibitor CAY10542, reduced demyelination by $25 \%$, and prevented the death of oligodendrocytes (16). The efficacy of COX-2 targeting has been confirmed in the cuprizone model as well, as celecoxib greatly reduced demyelination (about 30\% reduction in the corpus callosum and complete recovery in the cortex) along with a full recovery of motor abilities (35). In this model, COX-2 expression exerts deleterious effects on the oligodendrocytes through the production of $\mathrm{PGE}_{2}$, with in turn contributes to loss of oligodendrocytes by interacting with the EP2 receptor: the administration of an EP2 antagonist to cuprizone mice showed similar protective effects as the ones induced by celecoxib (35).EAE mice treated with an inhibitor of $\mathrm{CPLA}_{2}$ showed marked beneficial activity (about $85 \%$ inhibition of disease severity) (26). Because of this observation, the question arises whether, the protective effect is mediated merely through the inhibition of the COX pathway or the inhibition of LOX activity is also involed. It has been shown that 5-LOX selective inhibition delayed the onset of EAE by about 5 days (26). Similarly, in the cuprizone model, 5-LOX inhibition resulted in reduced axonal pathology and ameliorated motor disabilities without any improvement in the demyelination severity (39). Overall, these data suggest that COX-2 and 5-LOX inhibition have some nonoverlapping activities (52).

\section{NSAIDs Administration: Future Perspectives}

Most of the currently available pharmacological medications for multiple sclerosis counteract the activity of the autoimmune system. Lymphocytes are the leading factors in the autoimmune-mediated mechanisms implicated in the disruption of myelin proteins and the death of oligodendrocytes. First-generation drugs (interferons and glatiramer acetate) and second-generation drugs (fingolimod, mitoxantrone, rituximab, ocrelizumab, ofatumumab, and others) reduce disease severity, progression, and relapses; their main mechanism of action include sequestration of lymphocytes in the lymph node, and reduction of their access to the brain (53-56). However, these drugs do not directly target the arachidonic acid metabolism. Based on the literature, NSAIDs are currently administered to patients if flu-like symptoms occur. However, growing evidence supports the hypothesis that COX-2 and 5-LOX enzymes promote downstream mechanisms that ultimately lead to oligodendrocyte degeneration and axon pathology, respectively, and that both contribute to the development of motor disabilities. The combination of COX-2 and 5-LOX selective inhibitors has the potential to improve multiple sclerosis pathology. Moreover, multiple sclerosis has been associated with platelet activation and augmented cardiovascular risk, which are considered as causal factors in the pathogenesis of the disease $(57,58)$. Interestingly, it has been recently observed that peripheral blood platelets of patients highly express COX-2 (58). In the light of these evidence, the administration of COX-2 selective NSAIDs could reduce both cardiovascular risk and the progression of multiple sclerosis. 


\section{Conclusion}

Several pharmacological studies, conducted in experimental animal models of multiple sclerosis, suggest that NSAIDs that selectively inhibit the COX-2 isoform represent promising medications for reducing oligodendrocytes apoptosis, demyelination, and motor dysfunction. In addition, it is suggested that 5-LOX inhibitors could be beneficial to counteract axonal pathology and to inhibit motor disabilities as well. The coadministration of COX-2 and 5-LOX inhibitor is a promising way forward for multiple sclerosis treatment.

Conflict of interest: The authors declare no potential conflicts of interest with respect to research, authorship, and/or publication of this article.

Copyright and permission statement: To the best of my knowledge, the materials included in this chapter do not violate copyright laws. All original sources have been appropriately acknowledged and/or referenced. Where relevant, appropriate permissions have been obtained from the original copyright holder(s).

\section{References}

1. McFarland HF, Martin R. Multiple sclerosis: A complicated picture of autoimmunity. Nat Immunol. 2007Sep;8(9):913-19. http://dx.doi.org/10.1038/ni1507

2. Benveniste EN, Merrill JE. Stimulation of oligodendroglial proliferation and maturation by interleukin-2. Nature. 1986 Jun;321(6070):610-13. http://dx.doi.org/10.1038/321610a0

3. Renner K, Hellerbrand S, Hermann F, Riedhammer C, Talke Y, Schiechl G., et al. IL-3 promotes the development of experimental autoimmune encephalitis. JCI Insight. 2016 Oct;1(16):e87157. http:// dx.doi.org/10.1172/jci.insight.87157

4. Zajicek JP, Wing NJ, Scolding DA. Compston, interactions between oligodendrocytes and microglia. A major role for complement and tumour necrosis factor in oligodendrocyte adherence and killing. Brain. 1992 Dec:115(Pt 6):1611-31. http://dx.doi.org/10.1093/brain/115.6.1611-a

5. Vartanian T, Li M, Zhao M, Stefansson K. Interferon-gamma-induced oligodendrocyte cell death: Implications for the pathogenesis of multiple sclerosis. Mol Med. 1995 Nov;1(7):732-43

6. Lucchinetti CF, Bruck W, Rodriguez M, Lassmann H. Distinct patterns of multiple sclerosis pathology indicates heterogeneity on pathogenesis. Brain Pathol. 1996 Jul;6(3):259-74. http://dx.doi. org/10.1111/j.1750-3639.1996.tb00854.x

7. Lassmann H. Cortical lesions in multiple sclerosis: Inflammation versus neurodegeneration. Brain. 2012 Oct;135(Pt 10):2904-5. http://dx.doi.org/10.1093/brain/aws260

8. Stys PK. Multiple sclerosis: Autoimmune disease or autoimmune reaction? Can J Neurol Sci. 2010 Sep;37(Suppl 2):16-23. http://dx.doi.org/10.1017/S0317167100022393

9. Pérez-Cerdá F, Sánchez-Gómez MV and Matute C. The link of inflammation and neurodegeneration in progressive multiple sclerosis. Multiple Sclerosis and Demyelinating Disorders. Cross Mark. 2016 July;1:9. https://doi.org/10.1186/s40893-016-0012-0

10. Palumbo S, Bosetti F. Alterations of brain eicosanoid synthetic pathway in multiple sclerosis and in animal models of demyelination: Role of cyclooxygenase-2. Prostaglandins Leukot Essent Fatty Acids. 2013 Sep;89(5):273-8. http://dx.doi.org/10.1016/j.plefa.2013.08.008

11. Rajda C, Pukoli D, Bende Z, Majláth Z, Vécsei L. Excitotoxins, mitochondrial and redox disturbances in multiple sclerosis. Int J Mol Sci. 2017 Feb;18(2):353. http://dx.doi.org/10.3390/ ijms 18020353 
12. Kiekkas P, Aretha D, Karga M, Karanikolas M. Self report may lead to underestimation of 'wrong dose' medication errors. Br J Clin Pharmacol. 2009 Dec;68(6):963-4. http://dx.doi.org/10.1111/j.13652125.2009.03530.x

13. Burman J, Svensson E, Fransson M, Loskog ASI, Zetterberg H, Raininko R, et al. The cerebrospinal fluid cytokine signature of multiple sclerosis: A homogenous response that does not conform to the Th1/Th2/Th17 convention. J Neuroimmunol. 2014;277:153-9. http://dx.doi.org/10.1016/j. jneuroim.2014.10.005

14. Khaibullin T, Ivanova V, Martynova E, Cherepnev G, Khabirov F, Granatov E, et al. Elevated levels of proinflammatory cytokines in cerebrospinal fluid of multiple sclerosis patients. Front Immunol. 2017 Oct;8(1/2):531. http://dx.doi.org/10.3389/fimmu.2017.00531

15. Carlson NG, Hill KE, Tsunoda I, Fujinami RS, Rose JW. The pathologic role for COX-2 in apoptotic oligodendrocytes in virus induced demyelinating disease: Implications for multiple sclerosis. J Neuroimmunol. 2006 Mar;174(1/2):21-31. http://dx.doi.org/10.1016/j.jneuroim.2006.01.008

16. Carlson NG, Rojas MA, Redd JW, Tang P, Wood B, Hill KE, et al. Cyclooxygenase-2 expression in oligodendrocytes increases sensitivity to excitotoxic death. J Neuroinflammation. 2010 Apr; 7:25. http:// dx.doi.org/10.1186/1742-2094-7-25

17. Rose JW, Hill KE, Watt HE, Carlson NG. Inflammatory cell expression of cyclooxygenase-2 in the multiple sclerosis lesion. J Neuroimmunol. 2004 Mar;149(1/2):40-9. http://dx.doi.org/10.1016/j. jneuroim.2003.12.021

18. Dore-Duffy P, Ho SY, Donovan C. Cerebrospinal fluid eicosanoid levels: Endogenous PGD2 and LTC4 synthesis by antigen-presenting cells that migrate to the central nervous system. Neurology. 1991 Feb;41(2 Pt 1):322-4. http://dx.doi.org/10.1212/WNL.41.2_Part_1.322

19. Rosnowska M, Cendrowski W, Sobocinnska Z, Wieczorkiewicz A. Prostaglandins E2 and F2 alpha in the cerebrospinal fluid in patients with multiple sclerosis. Acta Med Pol. 1981 Jan;22(1):97-103.

20. Bolton C, Turner AM, Turk JL. Prostaglandin levels in cerebrospinal fluid from multiple sclerosis patients in remission and relapse. J Neuroimmunol. 1984; Jun;6(3):151-9. http://dx.doi. org/10.1016/0165-5728(84)90002-X

21. Dore-Duffy P, Donaldson JO, Koff T, Longo M, Perry W. Prostaglandin release in multiple sclerosis: Correlation with disease activity. Neurology 1986 Dec;36(12):1587-90. http://dx.doi.org/10.1212/ WNL.36.12.1587

22. Neu I, Mallinger J, Wildfeuer A, Mehlber L. Leukotrienes in the cerebrospinal fluid of multiple sclerosis patients. Acta Neurol Scand. 1992 Dec;86(6):586-7. http://dx.doi.org/10.1111/j.1600-0404.1992. tb05491.x

23. Neu IS, Metzger G, Zschocke J, Zelezny R, Mayatepek E. Leukotrienes in patients with clinically active multiple sclerosis. Acta Neurol Scand. 2001 Mar; 105(1):63-6. http://dx.doi. org/10.1034/j.1600-0404.2002.00070.x

24. Whitney LW, Ludwin SK, McFarland HF, Biddison WE. Microarray analysis of gene expression in multiple sclerosis and EAE identifies 5-lipoxygenase as a component of inflammatory lesions. J Neuroimmunol. 2001 Dec;12(1/2):40-8. http://dx.doi.org/10.1016/S0165-5728(01)00438-6

25. Marusic S, Leach MW, Pelker JW, Azoitei ML, Uozumi N, Cui J, et al. Cytosolic phospholipase A2 alpha-deficient mice are resistant to experimental autoimmune encephalomyelitis. J Exp Med. 2005 Sep;202(6):841-51. http://dx.doi.org/10.1084/jem.20050665

26. Marusic S, Thakker P, Pelker JW, Stedman NL, Lee KL, McKew JC, et al. Blockade of cytosolic phospholipase A2 alpha prevents experimental autoimmune encephalomyelitis and diminishes development of Thl and Th17 responses. J Neuroimmunol. 2008 Oct;204(1/2):29-37. http://dx.doi. org/10.1016/j.jneuroim.2008.08.012

27. Kihara Y, Matsushita T, Kita Y, Uematsu S, Akira S, Kira J, et al. Targeted lipidomics reveals mPGES-1-PGE2 as a therapeutic target for multiple sclerosis. Proc Natl Acad Sci U S A. 2009 Dec 10;106(51):21807-12. http://dx.doi.org/10.1073/pnas.0906891106

28. Aloisi F, Serafini B, Adorini L. Glia-T cell dialogue. J Neuroimmunol. 2000 Jul 24;107(2):111. http:// dx.doi.org/10.1016/S0165-5728(00)00231-9

29. Deininger MH, Schluesener HJ. Cyclooxygenases-1 and -2 are differentially localized to microglia and endothelium in rat EAE and glioma. J Neuroimmunol. 1999 Mar;95(1/2):202-8. http://dx.doi. org/10.1016/S0165-5728(98)00257-4 
30. Esaki Y, Li Y, Sakata D, Yao C, Segi-Nishida E, Matsuoka T, et al. Dual roles of PGE2-EP4 signaling in mouse experimental autoimmune encephalomyelitis. Proc Natl Acad Sci U S A. 2010 Jun 23;107(27):12233-8. http://dx.doi.org/10.1073/pnas.0915112107

31. Ayoub SS, Wood EG, Hassan SU, Bolton C. Cyclooxygenase expression and prostaglandin levels in central nervous system tissues during the course of chronic relapsing experimental autoimmune encephalomyelitis (EAE). Inflamm Res. 2011 Jun;60(10):919-28. http://dx.doi.org/10.1007/ s00011-011-0352-3

32. Molina-Holgado E, Arévalo-Martín A, Ortiz S, Vela JM, Guaza C. Theiler's virus infection induces the expression of cyclooxygenase- 2 in murine astrocytes: Inhibition by the anti-inflammatory cytokines interleukin-4 and interleukin-10. Neurosci Lett. 2002 May;324(3):237-41. http://dx.doi. org/10.1016/S0304-3940(02)00209-4

33. Kim SJ, Jin YH, Kim BS. Prostaglandin E2 produced following infection with Theiler's virus promotes the pathogenesis of demyelinating disease. PLoS One. 2017 Apr;12(4):e0176406. http://dx.doi. org/10.1371/journal.pone.0176406

34. Palumbo S, Toscano CD, Parente L, Weigert R, Bosetti F. Time-dependent changes in the brain arachidonic acid cascade during cuprizone-induced demyelination and remyelination. Prostaglandins Leukot Essent Fatty Acids. 2011 Jul;85(1):29-35. http://dx.doi.org/10.1016/j.plefa.2011.04.001

35. Palumbo S, Toscano CD, Parente L, Weigert R, Bosetti F. The cyclooxygenase-2 pathway via the PGE(2) EP2 receptor contributes to oligodendrocytes apoptosis in cuprizone-induced demyelination. J Neurochem. 2011 May;121(3):418-27. http://dx.doi.org/10.1111/j.1471-4159.2011.07363.x

36. Kihara Y, Yokomizo T, Kunita A, Morishita Y, Fukayama M, Ishii S, et al. The leukotriene B4 receptor, BLT1, is required for the induction of experimental autoimmune encephalomyelitis. Biochem Biophys Res Commun. 2010;Apr 9;394(3):673-8. http://dx.doi.org/10.1016/j.bbrc.2010.03.049

37. Lee W, Su Kim H, Lee GR. Leukotrienes induce the migration of Th17 cells. Immunol Cell Biol. 2015 May-Jun;93(5):472-9. http://dx.doi.org/10.1038/icb.2014.104

38. Wang L, Du C, Lv J, Wei W, Cui Y, Xie X. Antiasthmatic drugs targeting the cysteinyl leukotriene receptor 1 alleviate central nervous system inflammatory cell infiltration and pathogenesis of experimental autoimmune encephalomyelitis. J Immunol. 2011 Sep;187(5):2336-45. http://dx.doi.org/10. 4049/jimmunol.1100333

39. Yoshikawa K, Palumbo S, Toscano CD, Bosetti F. Inhibition of 5-lipoxygenase activity in mice during cuprizone-induced demyelination attenuates neuroinflammation, motor dysfunction and axonal damage. Prostaglandins Leukot Essent Fatty Acids. 2011 Jul;85(1):43-52. http://dx.doi.org/10.1016/j. plefa.2011.04.022

40. FitzGerald GA, Patrono C. The coxibs, selective inhibitors of cyclooxygenase-2. N Engl J Med. 2001 Aug;345(6):433-42. http://dx.doi.org/10.1056/NEJM200108093450607

41. Munschauer FE, Kinkel RP. Managing side effects of interferon-beta in patients with relapsingremitting multiple sclerosis. Clin Ther. 1997 Jan;19(5):883-93. http://dx.doi.org/10.1016/ S0149-2918(97)80042-2

42. Reess J, Haas J, Gabriel K, Fuhlrott A, Fiola M. Both paracetamol and ibuprofen are equally effective in managing flu-like symptoms in relapsing-remitting multiple sclerosis patients during interferon beta-la (AVONEX) therapy. Mult Scler. 2002 Apr;8(1):15-18. http://dx.doi. org/10.1191/1352458502ms771sr

43. Mora JS, Kao KP, Munsat TL. Indomethacin reduces the side effects of intrathecal interferon. N Engl J Med. 1984 Jan;310(2):126-7. http://dx.doi.org/10.1056/NEJM198401123100219

44. Río J, Nos C, Bonaventura I, Arroyo R, Genis D, Sureda B, et al. Corticosteroids, ibuprofen, and acetaminophen for IFNbeta-1a flu symptoms in MS: A randomized trial. Neurology. 2004 Aug;63(3):525-8. http://dx.doi.org/10.1212/01.WNL.0000133206.44931.25

45. Brandes DW, Bigley K, Hornstein W, Cohen H, Au W, Shubin R. Alleviating flu-like symptoms with dose titration and analgesics in MS patients on intramuscular interferon beta-la therapy: A pilot study. Curr Med Res Opin. 2007 Jul;23(7):1667-2. http://dx.doi.org/10.1185/030079907X210741

46. Leuschen MP, Filipi M, Healey K. A randomized open label study of pain medications (naproxen, acetaminophen and ibuprofen) for controlling side effects during initiation of IFN beta-la therapy and during its ongoing use for relapsing-remitting multiple sclerosis. Mult Scler. 2004 Dec;10(6):636-42. http://dx.doi.org/10.1191/1352458504msl114oa 
47. Wingerchuk DM, Benarroch EE, O'Brien PC, Keegan BM, Lucchinetti CF, Noseworthy JH, et al. A randomized controlled crossover trial of aspirin for fatigue in multiple sclerosis. Neurology. 2005 Apr;64(7):1267-9. http://dx.doi.org/10.1212/01.WNL.0000156803.23698.9A

48. Reder AT, Thapar M, Sapugay AM, Jensen MA. Eicosenoids modify experimental allergic encephalomyelitis. Am J Ther. 1995 Sep;2(9):711-20. http://dx.doi.org/10.1097/00045391-199509000-00020

49. Miyamoto K, Miyake S, Mizuno M, Oka N, Kusunoki S, Yamamura T. Selective COX-2 inhibitor celecoxib prevents experimental autoimmune encephalomyelitis through COX-2-independent pathway. Brain. 2006 Aug;129(Pt 8):1984-92. http://dx.doi.org/10.1093/brain/awl170

50. Muthian G, Raikwar HP, Johnson C, Rajasingh J, Kalgutkar A, Marnett LJ, et al. COX-2 inhibitors modulate IL-12 signaling through JAK-STAT pathway leading to Thl response in experimental allergic encephalomyelitis. J Clin Immunol. 2006 Jan;26(1):73-85. http://dx.doi.org/10.1007/ s10875-006-8787-y

51. Ni J1, Shu YY, Zhu YN, Fu YF, Tang W, Zhong XG, et al. COX-2 inhibitors ameliorate experimental autoimmune encephalomyelitis through modulating IFN-gamma and IL-10 production by inhibiting T-bet expression. J Neuroimmunol. 2007;May;186(1/2):94-103. http://dx.doi.org/10.1016/j. jneuroim.2007.03.012

52. Kong W, Hooper KM, Ganea D. The natural dual cyclooxygenase and 5-lipoxygenase inhibitor flavocoxid is protective in EAE through effects on Thl/Th17 differentiation and macrophage/microglia activation. Brain Behav Immun. 2016 Mar;53:59-71. http://dx.doi.org/10.1016/j.bbi.2015.11.002

53. Bar-Or A, Calabresi PA, Arnold D, Markowitz C, Shafer S, Kasper LH, et al. Rituximab in relapsingremitting multiple sclerosis: A 72-week, open-label, phase I trial. Ann Neurol. 2008 Mar;63(3):395-400. http://dx.doi.org/10.1002/ana.21363

54. Kappos L, Li D, Calabresi PA, O'Connor P, Bar-Or A, Barkhof F, et al. Ocrelizumab in relapsingremitting multiple sclerosis: A phase 2, randomised, placebo-controlled, multicentre trial. Lancet. 2011 Nov;378(9805):1779-87. http://dx.doi.org/10.1016/S0140-6736(11)61649-8

55. Menge T, Weber MS, Hemmer B, Kieseier BC, von Büdingen HC, Warnke C, et al. Disease-modifying agents for multiple sclerosis: Recent advances and future prospects. Drugs. 2008 Nov;68(17):2445-68. http://dx.doi.org/10.2165/0003495-200868170-00004

56. Rice GP. Treatment of secondary progressive multiple sclerosis: Current recommendations and future prospects. BioDrugs. 1999 Nov;12(4):267-77. http://dx.doi.org/10.2165/00063030-199912040-00004

57. Jadidi D, Mohammadi M, Moradi T. High risk of cardiovascular diseases after diagnosis of multiple sclerosis. Mult Scler. 2013 Jan;19(10):1336-40. http://dx.doi.org/10.1177/1352458513475833

58. Morel A, Miller E, Bijak M, Saluk J. The increased level of COX-dependent arachidonic acid metabolism in blood platelets from secondary progressive multiple sclerosis patients. Mol Cell Biochem. 2016 Aug;420(1/2):85-94. http://dx.doi.org/10.1007/s11010-016-2770-6 